\title{
SISTEM MANAJEMEN SURAT BERBASIS WEB DI STMIK KOMPUTAMA MAJENANG
}

\author{
Beny Riswanto ${ }^{[1]}$, Rahardika Faisal Putra ${ }^{[2]}$ \\ STMIK Komputama Majenang ${ }^{[1]}$, Program Studi Teknik Informatika STMIK Komputama Majenang ${ }^{[2]}$ \\ Jl. Raya Majenang-Cimanggu Km 8 No. 99 Cilempuyang Kec. Cimanggu, Kab. Cilacap 53256 \\ E-mail : benyriswanto@gmail.com ${ }^{[1]}, \underline{\text { rahardikaputra96@gmail.com }{ }^{[2]}}$
}

\begin{abstract}
In the agency administration, the letter is an important means. Important information related to the agency and the secret is embodied in it. The timeliness of receipt of both outgoing and incoming mail should also be considered, therefore the management of incoming and outgoing mail must be implemented correctly.

At this time, the procedure is applied to the management of incoming and outgoing mail to the Division of Administration of the STMIK Komputama Majenang from receipt, manufacture, storage, documentation, to verify the letter, all done conventionally. Documentation of incoming and outgoing mail only in the form of writing in the ledger. While on the stage of filing a letter only a hardcopy document storage.

The Administration of STMIK Komputama Majenang felt the need to change the mail management method they are currently using, into a computerized and automated mail management method. With the Incoming and Outgoing Mail Management Information System, it is expected to be able to manage incoming and outgoing mail according to the specified flow, and can solve current problems. The filing of letters is done electronically, namely the storage of softcopy documents, and is equipped with reports of incoming and outgoing letters both daily and per period. In addition, this application also helps monitor the disposition of letters at the verification stage. The research methods used to solve various problems that occur are literature, observation, interviews, data and system analysis, system design, program development, program testing, program implementation. The result of this research is to produce an application that can manage incoming and outgoing mail according to the specified flow, and can solve current problems.
\end{abstract}

Key Word : Management information system, incoming and outgoing mail, website, php

\section{Latar belakang}

Perkembangan terknologi komputer dan sistem informasi pada saat ini telah mengalami peningkatan yang sangat pesat, dimana hal ini sejalan dengan kebutuhan masyarakat terhadap informasi. Masyarakat saat ini cenderung cepat dalam mengikuti arus perkembangan teknologi menuntut adanya ketersediaan informasi yang cepat, tepat dan akurat. Setiap instansi, baik instansi pemerintahan maupun swasta pasti membutuhkan sistem informasi yang mampu menunjang kinerjanya untuk mendapatkan serta menghasilkan informasi dengan cara yang lebih efektif dan efisien.

Seperti halnya pada STMIK Komputama Majenang masih memerlukan penanganan prosedur tata persuratan yang baik. Proses yang dilakukan selama ini masih menggunakan cara 
manual yang akan mengakibatkan kesulitan dalam pencarian data, keterlambatan dalam menyelesaikan atau tindak lanjut dari surat dan terjadi kesalahan pada penomoran surat masuk dan surat keluar. Semua proses keluar masuk surat dicatat dalam sebuah buku besar.

Hal ini tidak menutup kemungkinan akan hilangnya beberapa buah surat. Hal ini juga akan menghambat usaha pencarian sebuah data. Berdasarkan pengamatan yang dilakukan di STMIK Komputama Majenang, perlu adanya suatu sistem yang dapat membantu dalam proses pengolahan surat, dalam hal ini penulis melakukan penelitian dengan judul : "Sistem Manajemen Surat Berbasis WEB Di STMIK Komputama Majenang”.

\section{Tinjauan Literatur}

A. Sistem Informasi

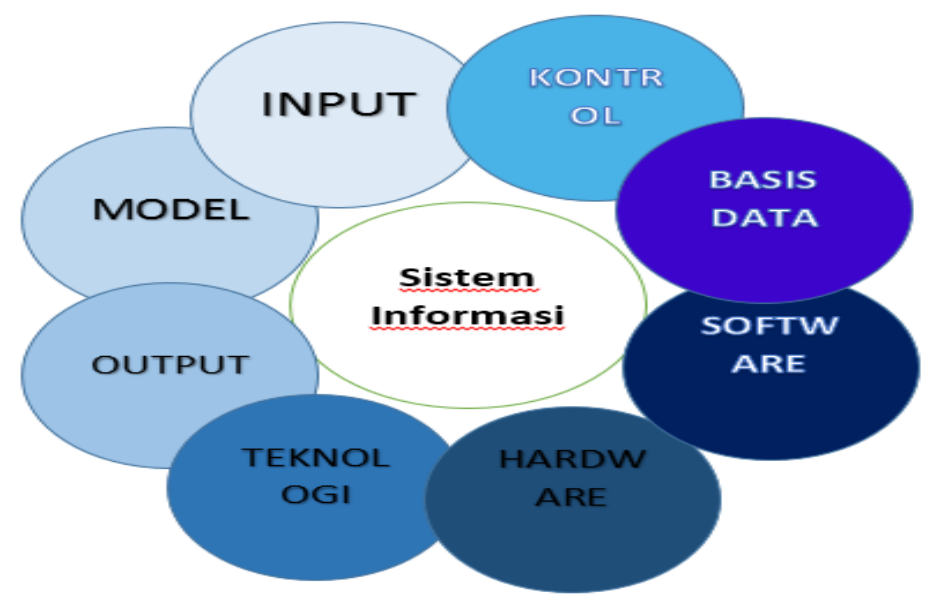

Gambar 1 Komponen - komponen di dalam sistem informasi

Sistem adalah sekumpulan prosedur yang saling berkaitan dan saling terhubung untuk melakukan suatu tugas bersama - sama. Informasi adalah hasil pengelolah data dari satu atau berbagai sumber yang kemudian diolah, sehinggga memberikan nilai, arti dan manfaat. Menurut Sarma Fuad di dalam papernya berjudul Information System Definition and Component, sistem informasi memiliki tujuh komponen (Pratama, 2014). Adapun ketujuh komponen yaitu Masukan (Input), Keluaran (Output), Perangkat Lunak (Software), Perangkat Keras (Hardware), Basis Data (Database), Kontrol dan Prosedur dan Teknologi dan Jaringan Komputer. Dibawah ini gambar tentang komponen - komponen sistem informasi.

B. Hypertext Preprocessor (PHP)

PHP adalah bahasa pemograman script server-side yang didesain untuk pengembangan web. Pada awalnya PHP merupakan kependekan dari Personal Home Page yang pertama kali dibuat oleh Rasmus Lerdorf pada tahun 1995 yang sekarang dikelola oleh The PHP Group (Andre, 2014). PHP disebut bahasa pemograman server side karena PHP diproses pada komputer server. Hal ini berbeda dibandingkan dengan bahasa pemrograman client-side seperti JavaScript yang diproses pada web browser (client). PHP sendiri dapat melakukan tugas - tugas yang dilakukan dengan mekanisme CGI seperti mengambil, mengumpulkan data dari basis data, melakukan generate halaman dinamis atau bahkan 
menerima dan mengirim cookie. CGI atau Common Gateway Interfaces adalah suatu mekanisme yang berjalan di web server, bertugas untuk melayani komunikasi dua arah antara web server dan web browser. Bebeapa kelebihan penggunaaan PHP adalah mendukung banyak basis data, mendukung berbagai macam web server, dapat digunakan oleh berbagai macam Platfotm Operation Sistem dan sebagainya.

\section{Database}

Menurut Rosa dan Shalahuddin (2015:43) "basis data merupakan salah satu bagian dalam rekayasa perangkat lunak yang terkomputerisasi dan bertujuan utama memelihara data yang sudah diolah atau media penyimpanan informasi agar dapat diakses dengan mudah dan cepat". Sedangkan menurut Yakub dan Hisbanarto (2015:25) menjelaskan, "basis data (database) merupakan kumpulan data yang saling berhubungan atau punya relasi".

MySQLi adalah ektensi PHP yang digunakan untuk melakukan koneksi ke database MySQL. Huruf i di akhir artinya Improved (Yang disempurnakan). Ada beberapa alasan mengapa kita harus migrasi kode PHP dari kode seperti mysql_query ke ektensi MySQLi ini. Catatan penting disini, dari sisi struktur project, struktur tabel dan interface tidak ada perubahan. Perubahan dari MySQL ke MySQLi ada dibelakang layar, terutama dari sisi performa menunjukan MySQLI lebih cepat dibanding MySQL.

\section{XAMPP}

Menurut Aryanto (2016:4), "Xampp merupakan sebuah aplikasi perangkat lunak pemrograman dan database yang di dalamnya terdapat berbagai macam aplikasi pemrograman seperti : Apache, HTTP, MySQL, database, bahasa pemrograman PHP dan Perl." Menurut Iqbal (2019:15), "Xampp merupakan sebuah software web server apache yang didalamnya sudah tersedia database server MySQL dan support PHP programming". Berdasarkan pengertian diatas dapat disimpulkan bahwa XAMPP adalah sebuah aplikasi perangkat lunak yang di dalamnya sudah tersedia database server MySQL dan support PHP programming.

\section{E. WEB}

Abdullah (2015:1), "Web dapat diartikan sekumpulan halaman yang terdiri dari beberapa laman yang berisi informasi dalam bentuk data digital baik berupa text, gambar, video, audio, dan animasi lainnya yang disediakan melalui jalur koneksi internet". Nilasari (2014:2), "Website atau sering disebut situs merupakan kumpulan halaman web yang dijalankan dari suatu alamat web domain. Bekti (2015:35), "Website merupakan kumpulan halaman-halaman yang digunakan untuk menampilkan informasi teks, gambar diam atau gerak, animasi, suara, dan atau gabungan dari semuanya, baik yang bersifat statis maupun dinamis yang membentuk satu rangkaian bangunan yang saling terkait, yang masingmasing masing dihubungkan dengan jaringan-jaringan halaman”.

F. Surat

Surat Menurut Kamus Besar Bahasa Indonesia "surat" merupakan kertas dan sebagainya yang tertulis atau secarik kertas sebagai keterangan atas sesuatu yang tertulis. Menurut Silmi (2002) surat adalah sehelai kertas atau lebih yang digunakan untuk mengadakan komunikasi secara tertulis. Urusan surat adalah suatu bagian yang penting dari pekerjaan administrasi. Surat pada hakekatnya adalah bentuk penuangan ide atau kehendak seseorang dalam bentuk tulisan. Secara terperinci, dikatakan pengertian surat sebagai berikut:

1. Bentuk pernyataan kehendak seseorang kepada orang lain melalui tulisan. 
2. Suatu media pencurahan perasaan, kehendak, pikiran dan tujuan seseorang untuk dapat diketahui orang lain.

3. Sarana komunikasi untuk menyampaikan informasi tertulis oleh suatu pihak kepada pihak lain.

4. Merupakan suatu bentuk gambaran suatu peristiwa atau keadaan yang dituangkan dalam bentuk tulisan.

Dengan demikian surat merupakan jembatan pengertian dan alat komunikasi bagi seseorang dan orang lain. Karena sifatnya yang demikian, maka surat-surat harus disusun secara singkat dan padat tetapi jelas dan tegas. Bahasa yang dipakai haruslah mudah dimengerti, sederhana,dan teratur.

G. Surat Masuk dan Surat Keluar

Surat masuk adalah semua jenis surat yang diterima dari instansi lain maupun dari perorangan, baik yang diterima melalui pos (kantor pos) maupun yang diterima dari kurir (pengiriman surat) dengan mempergunakan buku pengiriman (ekspedisi). Menurut Wursanto (1991) surat masuk adalah semua jenis surat yang diterima dari organisasi/instansi maupun perorangan, baik yang diterima melalui pos (kantor pos), maupun yang diterima dari kurir (pengantar surat) dengan mempergunakan buku pengiriman. Surat Keluar adalah surat yang akan dikeluarkan oleh organisasi /instansi yang ditujukan ke organisasi lain diluar organisasi itu sendiri. Menurut Wursanto (1994) surat keluar adalah surat yang sudah lengkap (bertanggal, bernomor, berstempel, dan telah di tanda tangani oleh berwenang) yang dibuat oleh instansi, kantor maupun lembaga yang ditujuankan kepada instansi, kantor atau lembaga lain. Menurut Widjaja (1990) surat keluar adalah surat yang dikeluarkan oleh organisasi atau instansi yang ditujukan kepada organisasi/perorangan diluar organisasi tersebut.

H. Arsip Surat

Menurut Hendi Haryadi dalam Mulyadi (2016:25) menyatakan bahwa arsip secara umum adalah wujud tulisan dalam bentuk corak teknis, bagaimanapun juga dalam keadaan tunggal, berkelompok, atau dalam suatu kesatuan bentuk fungsi dari usaha perencanaan, pelaksanaan, dan penyelenggaraan kehidupan umumnya, dan arsip secara khusus adalah kumpulan surat atau bahan penolong lainnya dengan memastikan suatu ingatan yang dibuat secara fisik (kasat mata) atau yuridis (sesuai dengan ketentuan hukum yang berlaku) dengan perkembangan organisasi, yang disimpan dan dipelihara selama diperlukan.

\section{Metodologi Penelitian}

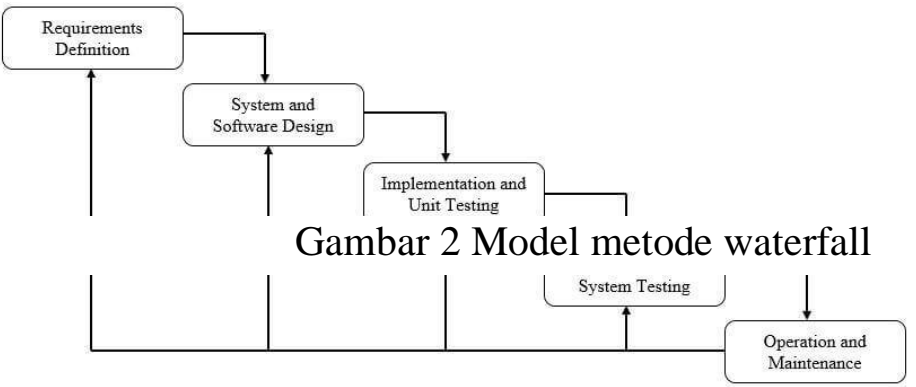


Pada tahapan pengembangan sistem ini penulis melakukan tahap demi tahap secara berurutan mulai dari Pengumpulan Data, Analisa Sistem, Design Sistem, Implementasi Sistem, dan Pemeliharaan Sistem. Adapun langkah-langkah yang dilakukan sebagai berikut :

1. Requirement Analysis

Tahapan metode waterfall yang pertama adalah mempersiapkan dan menganalisa kebutuhan dari software yang akan dikerjakan. Informasi dan insight yang diperoleh dapat berupa dari hasil wawancara, survei, studi literatur, observasi atau pengamatan, hingga diskusi.

a. Pengumpulan data

Pengumpulan data dilakukan agar dapat mengetahui sistem yang akan dikembangkan dan data-data yang diperlukan adalah data yang akurat. Untuk memperoleh data yang benar-benar akurat maka dilakukan beberapa proses pengumpulan data yaitu:

1) Pengamatan

Selama riset penulis mengamati secara langsung kegiatan-kegiatan pada STMIK Komputama Majenang, yang berkaitan dengan pengarsipan surat masuk, surat keluar dan disposisi surat pada unityang bertanggung jawab terhadap tugas ini.

2) Wawancara

Wawancara dilakukan dengan memberikan pertanyaan langsung kepada staff administrasi terkait dengan proses atau SOP proses pengarsipan surat, surat masuk, surat keluar dan disposisi surat.

3) Studi Pustaka

Pada tahapan penulis mendapatkan sumber referensi dari buku, makalah jurnal atau referensi lainnya yang berkaitan dengan pengembangan sistem informasi pengarsipan surat masuk dan surat keluar.

4) Kajian Penelitian Serupa

Selain berdasarkan kebutuhan dari pihak instansi, proses penelitian ini juga menggunakan beberapa penelitian lain sebagai rujuka. Beberapa penelitian serupa yang digunakan yaitu :

a) Penelitian Ade Suryadi ${ }^{(1)}$, Yuli Siti Zulaikhah ${ }^{(2)}$ dalam jurnal Khatulistiwa Informatika, Vol. Vii, No. 1 Juni 2019 yang berjudul Rancang Bangun Sistem Pengelolaan Arsip Surat Berbasis Web Menggunakan Metode Waterfall. Penelitian tersebut memuat tentang proses perancangan sistem pengelolaan surat dengan menggunakan metode pengembangan waterfall di Kantor Desa Karangrau Banyumas.

b) Penelitian Kurnia Ahmad Husaein dalam jurnal Ilmiah MEDIA SISFO yang berjudul Perancangan Sistem Informasi Manajemen Surat (SIMURAT) Pada AKAKOM Stephen Jambi. Penelitian tersebut memuat tentang perancangan sistem infomasi manajemen surat masuk dan keluar $\mathrm{k}$ berbasis web yang dapat mengatasi permasalahan dalam manajemen surat masuk dan surat keluar.

c) Penelitian Agus Cahyo Nugroho dalam jurnal Jurnal Pengembangan IT (JPIT), Vol.04, No.02, Mei 2019 yang berjudul Rancang Bangun Sistem Informasi Manajemen Surat Tugas Berbasis Web Menggunakan Waterfall Model. Penelitian tersebut memuat tentang Rancang Bangun Sistem Informasi Manajemen Surat menggunkan Bahasa PHP .

d) Penelitian Fauzan Masykur ${ }^{(1)}$, Ibnu Makruf Pandu Atmaja ${ }^{(2)}$ dalam jurnal IJNS 
- Indonesian Journal on Networking and Security - Volume 4 No 3 - Juli 2015

- ijns.org yang berjudul Sistem Administrasi Pengelolaan Arsip Surat Masuk

Dan Surat Keluar Berbasis Web. Penelitian tersebut memuat tentang Bagaimana merancang dan membuat Aplikasi Administrasi di SMK Negeri 1 Magetan khususnya bagian administrasi surat.

b. Analisa Sistem

Pada tahap ini dilakukan identifikasi kebutuhan dari sistem yang akan dikembangkan. Berdasarkan data yang diperoleh pada tahapan pengumpulan data, selanjutnya dilakukan analisa kebutuhan sistem yang akan dikembangkan. Proses analisa sistem ini nantinya akan memberikan gambaran jelas untuk tahapan berikutnya.

2. System and Software Design

Pada tahapan ini dilakukan proses desain sistem diantaranya use case diagram, activity diagram, class diagram, berdasarkan proses analisa yang dilakukan pada tahapan ke 1. Selanjutnya pada tahapan ini juga digambarkan rancangan input, dan rancangan output dari sistem informasi manajemen surat.

3. Implementation and Unit Testing

Pada tahap ini dilakukan pembuatan aplikasi atau sistem berbasis komputer yang akan dikembangkan berdasarkan rancangan pada tahap sebelumnya dengan menggunakan bahasa pemrograman PHP framework (Codeigniter) dengan MySQLi sebagai database. Setelah sistem dikembangkan selanjutnya dilakukan pengujian terhadap modul yang dihasilkan dengan harapan dapat diketahui apakah sistem yang dikembangkan telah sesuai dengan kebutuhan tanpa adanya kesalahan.

4. Integration and Testing

Tahap yang keempat, masuk dalam proses integrasi dan pengujian sistem. Pada tahap ini, akan dilakukan penggabungan modul yang sudah dibuat pada tahap sebelumnya. Setelah proses integrasi sistem telah selesai, berikutnya masuk pada pengujian modul.

Yang bertujuan untuk mengetahui apakah perangkat lunak sudah sesuai dengan desain, dan fungsionalitas dari aplikasi apakah berjalan dengan baik atau tidak. Jadi, dengan adanya tahap pengujian, maka dapat mencegah terjadinya kesalahan, bug, atau error pada program sebelum masuk pada tahap produksi.

\section{Operation and Maintenance}

Pada tahap ini dilakukan proses maintenence / perawatan sistem yang telah dikembangkan. Maintenence / perawatan yang dimaksud yaitu memperbaiki kesalahan yang tidak ditemukan pada tahap sebelumnya serta penambahan modul baru sesuai dengan kebutuhan.

Tahapan demi tahapan digunakan sebagai acuan dalam proses pengembangan sistem secara keseluruhan. Tahapan yang dilakukan memberikan gambaran bagaimana proses pengembangan sistem secara keseluruhan mulai dari pengumpulan data, analisa, desain sistem, implementasi dan perawatan. Penerapan metode waterfall dilakukan sampai dengan proses penyelesaian akhir perangkat lunak dan proses pengujian untuk membuktikan bahwa sistem yang telah dikembangkan layak untuk digunakan.

\section{Hasil Dan Pembahasan}

Berdasarkan hasil penelitian yang dilakukan pada sistem manajemen surat masuk dan surat keluar hasil akhir dari semua kegiatan dan tahapan-tahapan pengembangan sistem yang telah dilakukan merupakan penerapan dari rancangan-rancangan yang terdiri dari desain file, desain 
input, dan desain output. Bahasa pemrograman yang digunakan dalam membangun sistem manajemen surat masuk dan keluar adalah PHP dan MYSQL. Pembuatan perancangan sistem manajemen surat masuk dan surat keluar untuk mengirim dan mendisposisi surat masuk dan surat keluar yang tentunya akan lebih mempermudah pengelolaan surat masuk dan surat keluar pada STMIK Komputama Majenang.

1. Alur kerja sistem manajemen surat masuk dan surat keluar.

Berikut ini adalah alur kerja dari proses pengarsipan menggunakan use case diagram dan Activity diagram pada sistem manajemen surat masuk dan surat keluar:

a. Use Case Diagram

Use Case diagram menggambarkan fungsionalitas yang diharapkan dari sebuah aplikasi yang hendak dikembangkan.

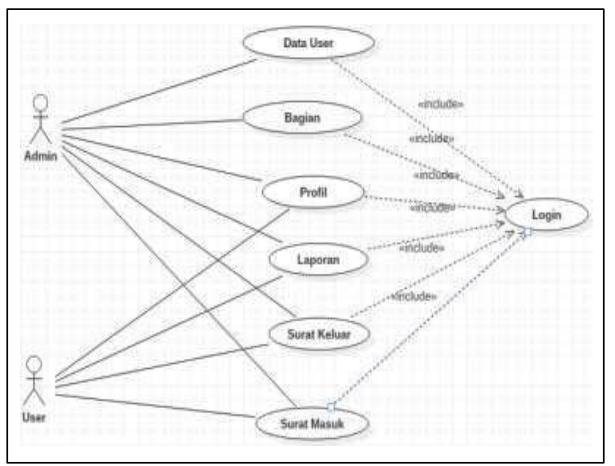

Gambar 3 Use case diagram sistem manajeman surat

Pada Use Case Diagram diatas, dapat dilihat bahwa Admin dapat mengakses seluruh activity yang ada dalam sistem, baik itu memasukkan data ataupun melihat serta mengunduh surat masuk dan surat keluar, tetapi user untuk hanya sebatas mengakses sistem tersebut dan tidak bisa menambahkan dan menghapus data user.

b. Activity Diagram pada Admin dan User

Form login dapat dilihat bahwa Admin langsung dapat mengakses aplikasi dengan memasukkan Username dan Password dengan benar.

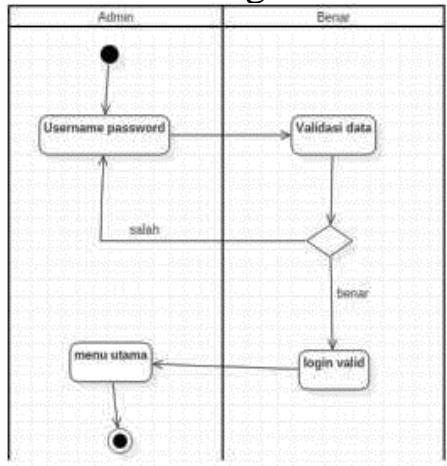

Gambar 4 Activity diagram form login admin

Form login dapat dilihat bahwa Admin dan User langsung dapat mengakses aplikasi dengan memasukkan Username dan Password dengan benar. 


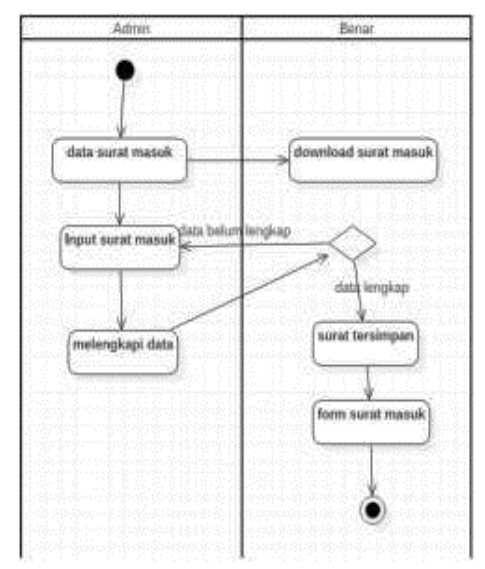

Gambar 5 Activity dagram form surat masuk admin dan User

Pada Form surat masuk dapat dilihat bahwa Admin dan User dapat menginput surat masuk dan dapat mendownload surat masuk yang sudah ada jika di perlukan.

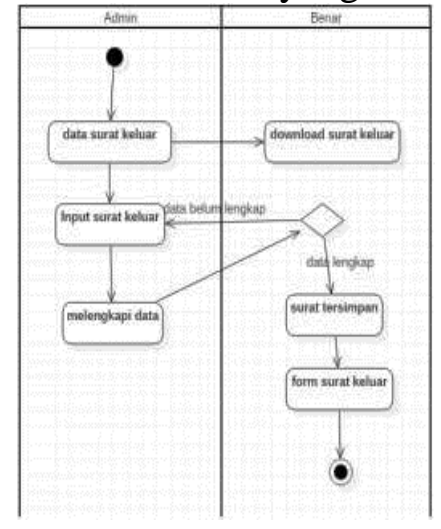

Gambar 6. Activity diagram form surat keluar admin

Form surat keluar dapat dilihat bahwa admin dapat menginput surat keluar dan dapat men-download surat masuk yang sudah ada jika di perlukan.

2. Perancangan Aplikasi Pengelolaan surat masuk dan surat keluar.

Perancangan sistem adalah untuk membuat aplikasi pengelolaan surat masuk dan surat keluar berbasis web ini yang dapat membantu pegawai untuk mengelola surat masuk dan keluar di STMIK Komputama Majenang. Perancangan sistem meliputi usecase diagram, activity diagram, ,tabel-tabel basis data, dan design interface.

a. Rancangan User Interface (UI)

Rancangan antar muka pengguna yang dihasilkan dari analisis penulis berupa rancangan screen, form, surat masuk, surat keluar dan dialog design.

1) Rancangan Halaman Login

Adapun halaman utama pada system manajemen surat yang tertara pada gambar 7 sebagai berikut. 


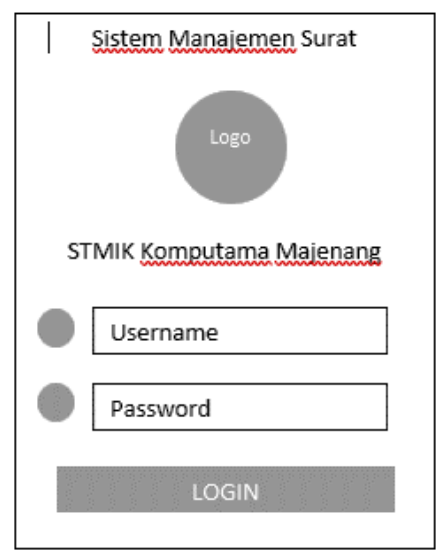

Gambar 7. Halaman login

Pada rancangan halaman login pengelolaan surat ada beberapa fitur yang diantaranya pengguna harus masuk terlebih dahulu dengan mengisi nama pengguna dan kode pengguna atau password.

2) Rancangan Halaman Utama

Adapun rancangan utama halaman admin dan user dapat dilihat pada gambar 4.12 dan gambar 8 sebagai berikut :

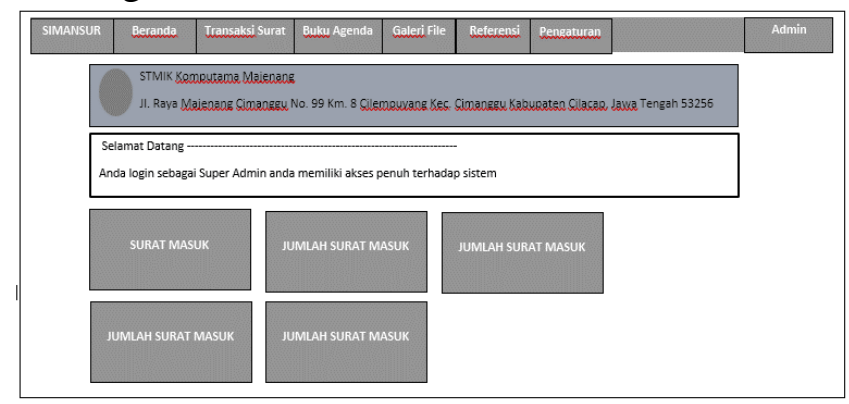

Gambar 8. Halaman utama admin

3) Rancangan Surat Masuk Admin dan User

Adapun rancangan surat admin masuk dapat dilihat pada gambar 9 sebagai berikut

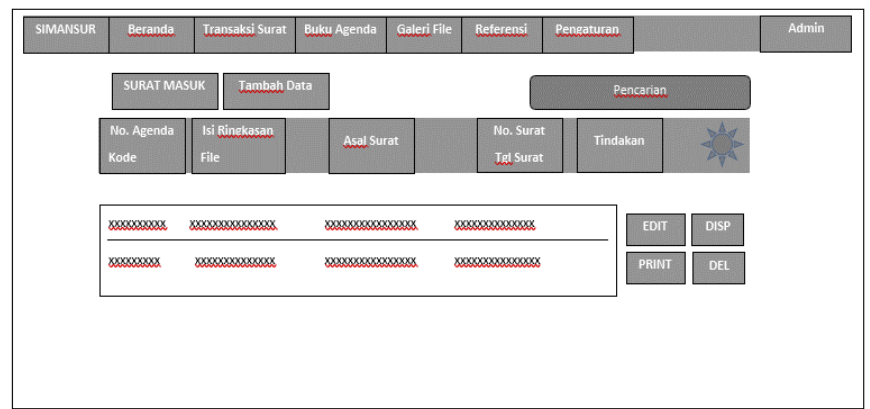

Gambar 9. Halaman rancangan surat masuk admin dan User

Pada rancangan surat masuk berisikan nomor agenda, isi file, asal surat, nomor dan tanggal surat serta tindakan atau opsi yang dimana admin dan user bisa mengubah, mendisposisi, print surat masuk serta menghapus surat masuk. 
4) Rancangan Surat Keluar Admin dan User

Adapun rancangan surat keluar Admin dan User masuk dapat dilihat pada gambar 10 sebagai berikut :

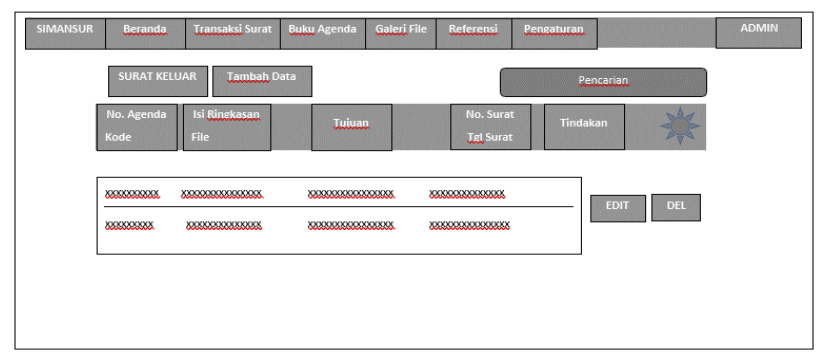

Gambar 10. Halaman rancangan surat keluar admin dan user

Pada rancangan surat keluar berisikan nomor agenda, isi file, asal surat, nomor dan tanggal surat serta tindakan atau opsi yang dimana pengguna bisa mengubah surat masuk serta menghapus surat keluar.

5) Rancangan Management User pada Admin

Adapun rancangan Management User pada Admin masuk dapat dilihat pada gambar 11 sebagai berikut :

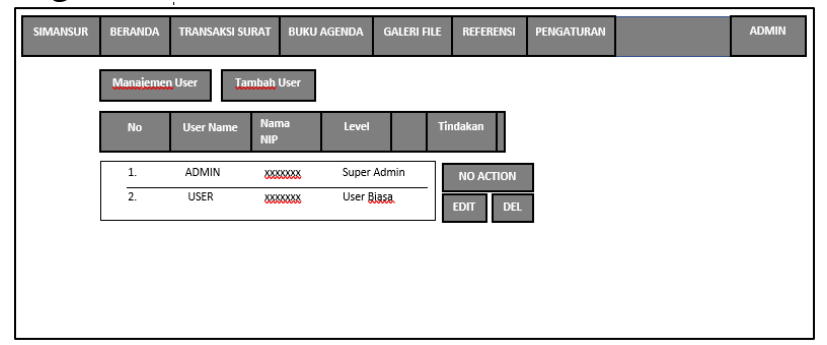

Gambar 11. Halaman rancangan management user

Pada rancangan management user ini yang dimana admin bisa menambahkan ataupun menghapus pengguna.

3. Implementasi Sistem Manajemen Surat

Hasil akhir dari semua kegiatan dan tahapan-tahapan pengembangan sistem yang telah dilakukan merupakan penerapan dari rancangan-rancangan yang telah diuraikan pada bab sebelumnya. Maka berikut ada penjelasan dari sistem manajemen sebagai berikut

a Form Login

Adapun form login pada sistem manajemen surat masuk dan keluar yang tertara pada gambar sebagai berikut

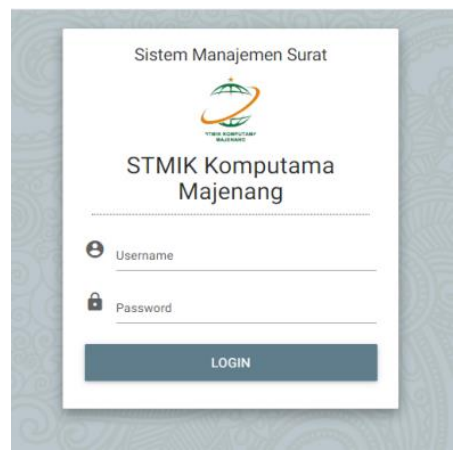

Gambar 12 Tampilan form login 
Pada form login aplikasi surat masuk dan surat keluar ada beberapa fitur untuk pengguna masuk ke aplikasi tersebut dengan memasukan nama pengguna dan kode pengguna atau password.

b Halaman utama

Adapun halaman utama sistem manajemen surat masuk dan surat kelua itu sendiri dapat dilihat pada gambar 13 sebagai berikut :

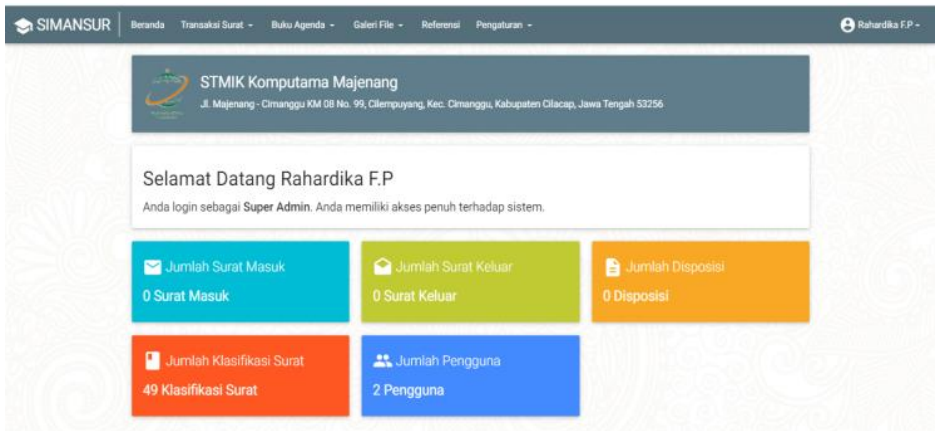

Gambar 13 Tampilan halaman utama/dashboard

Pada halaman utama sistem manajemen surat masuk dan surat keluar di STMIK Komputama Majenang adalah dimana ada header pada dashboard yang bertuliskan STMIK Komputama Majenang, dan diatas nya terdapat beberapa fitur seperti menu beranda, transaksi surat, buku agenda, galeri serta pengaturan untuk pengguna serta beberapa notice jumlah surat masuk, surat keluar, disposisi, klasifikasi surat dan jumlah pengguna.

c Transaksi Surat Masuk

Adapun halaman transaksi surat masuk pada aplikasi pengelolaan surat masuk dan surat kelua itu sendiri dapat dilihat pada gambar 14 sebagai berikut

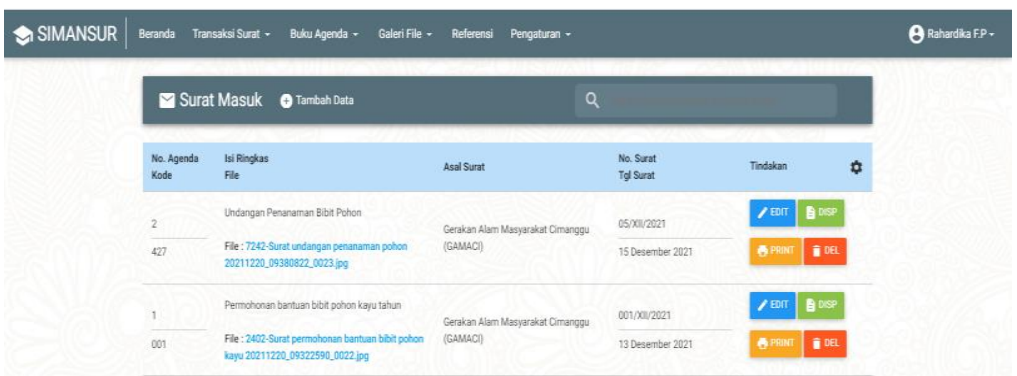

Gambar 14. Halaman transaksi surat masuk

Pada halaman surat masuk berisikan nomor agenda, isi file, asal surat, nomor dan tanggal surat serta tindakan atau opsi yang dimana pengguna bisa mengubah, mendisposisi, print surat masuk serta menghapus surat masuk.

\section{d Transaksi Surat Keluar}

Adapun halaman transaksi surat keluar pada sistem manajemen surat masuk dan surat keluar itu sendiri dapat dilihat pada gambar 15 sebagai berikut : 


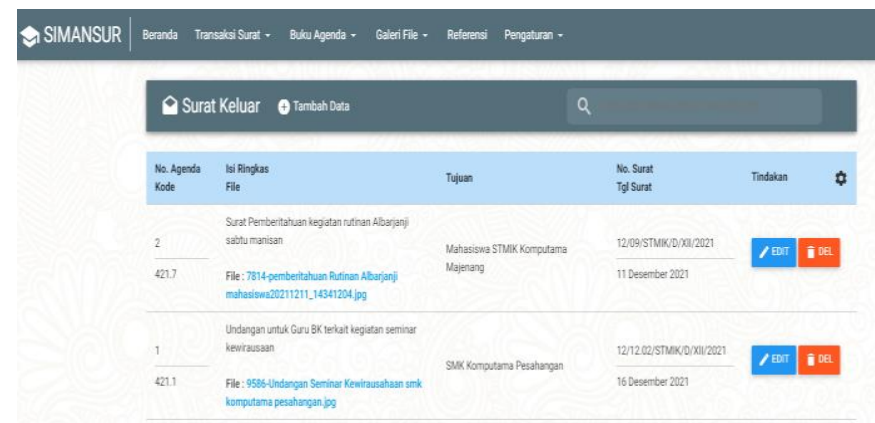

Gambar 15. Halaman transaksi surat keluar

Pada halaman surat keluar berisikan nomor agenda, isi file, tujuan surat, nomor dan tanggal surat serta tindakan atau opsi yang dimana pengguna bisa mengubah, serta menghapus surat masuk.

e Buku Agenda Surat Masuk

Adapun halaman buku agenda surat masuk pada sistem manajemen surat masuk dan surat keluar itu sendiri dapat dilihat pada gambar 16 sebagai berikut :

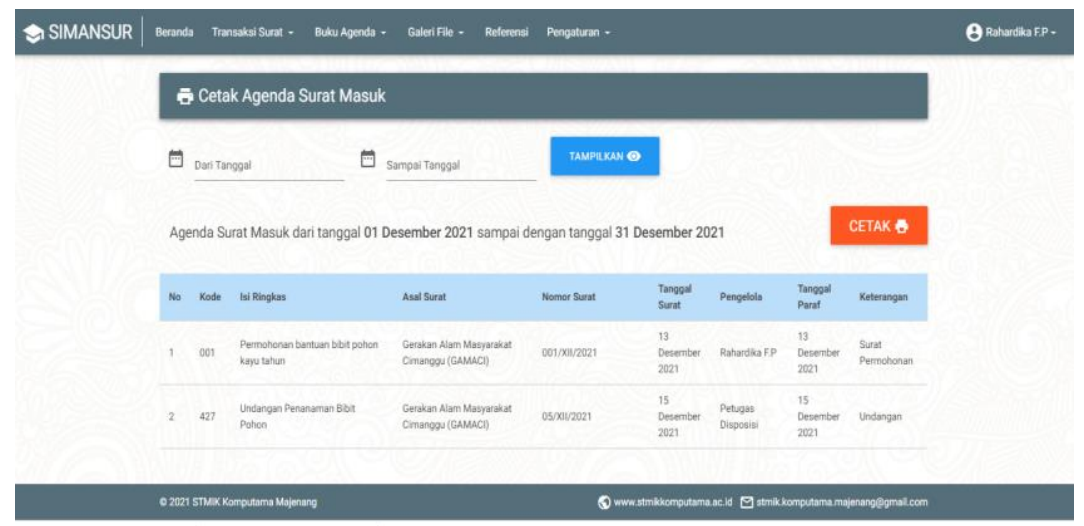

Gambar 16. Halaman buku agenda surat masuk

f Buku Agenda Surat Keluar

Adapun halaman buku agenda surat keluar pada sistem manajemen surat masuk dan surat keluar itu sendiri dapat dilihat pada gambar 17 sebagai berikut :

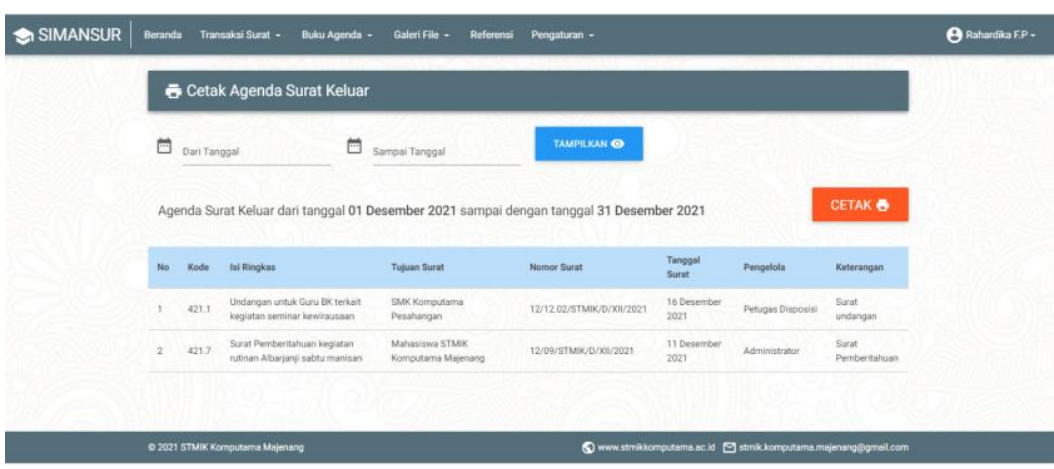

Gambar 17. Halaman buku agenda surat keluar 
g Halaman Tambah Data Surat Masuk

Adapun halaman tambah data surat masuk pada sistem manajemen surat masuk dan surat kelua itu sendiri dapat dilihat pada gambar 18 sebagai berikut :

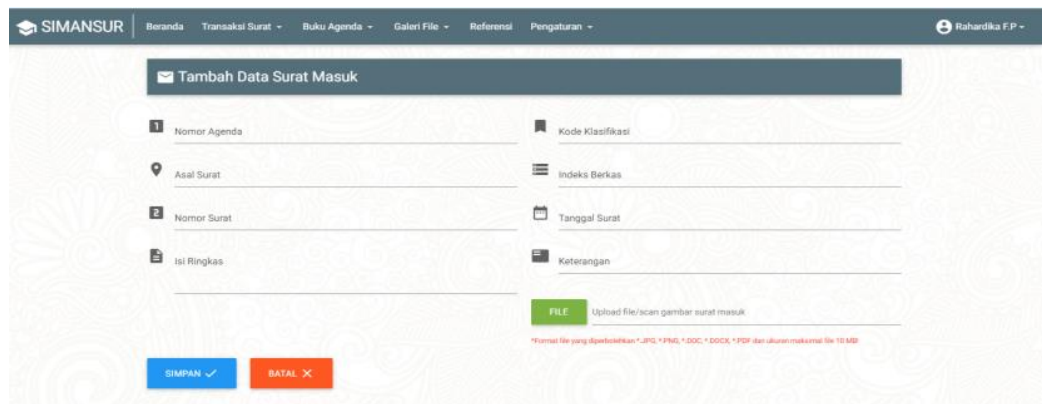

Gambar 18. Halaman tambah data surat masuk

Pada halaman tambah surat masuk ada beberapa fitur yang nantinya pengguna akan mengisi nomor agenda surat, asal surat, nomor surat, isi ringkas pada surat masuk, kode klasifikasi, tanggal surat, keterangan surat serta file foto surat yang nanti nya akan di upload di fitur tersebut.

h Halaman Tambah Data Surat Keluar

Adapun halaman tambah data surat keluar pada sistem manajemen surat masuk dan surat kelua itu sendiri dapat dilihat pada gambar 19 sebagai berikut :

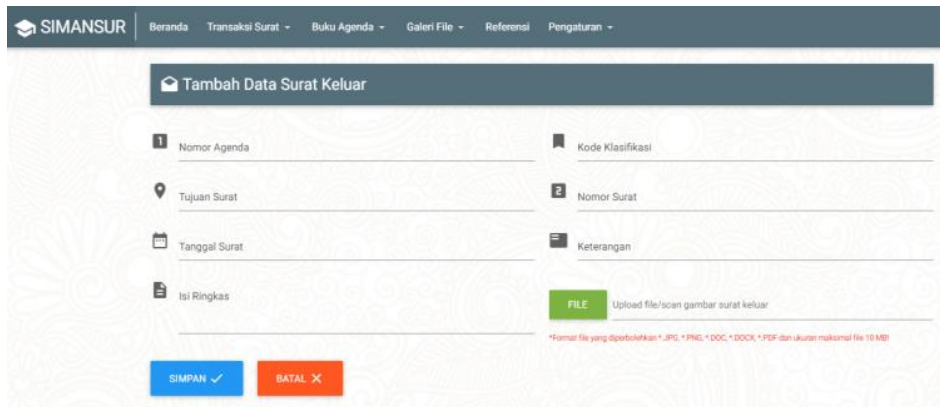

Gambar 19. Halaman tambah data surat keluar

Pada halaman tambah surat masuk ada beberapa fitur yang nantinya pengguna akan mengisi nomor agenda surat, asal surat, nomor surat, isi ringkas pada surat keluar, kode klasifikasi, tanggal surat, keterangan surat serta file foto surat yang nanti nya akan di upload di fitur tersebut.

i Halaman Management User pada Admin

Adapun hasil Management User pada Admin masuk dapat dilihat pada gambar 20 sebagai berikut : 


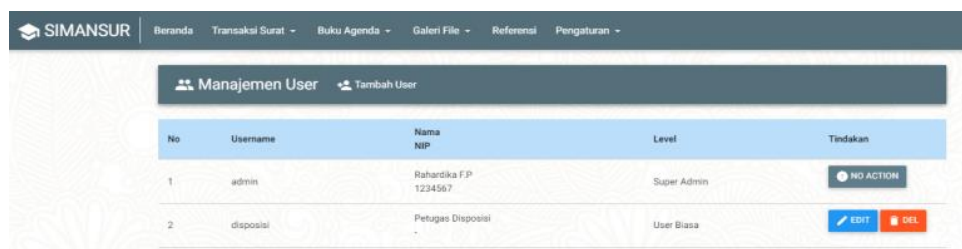

Gambar 20. Halaman management user dan admin

Pada halaman hasil management user ini yang dimana admin bisa menambahkan ataupun menghapus pengguna.

j Tampilan Output Aplikasi

Tampilan output merupakan tampilan hasil surat masuk dan surat keluar yang ada pada sistem manajemen surat STMIK Komputama Majenang. Ada 3 tampilan output yaitu

1) Transaksi Surat Masuk

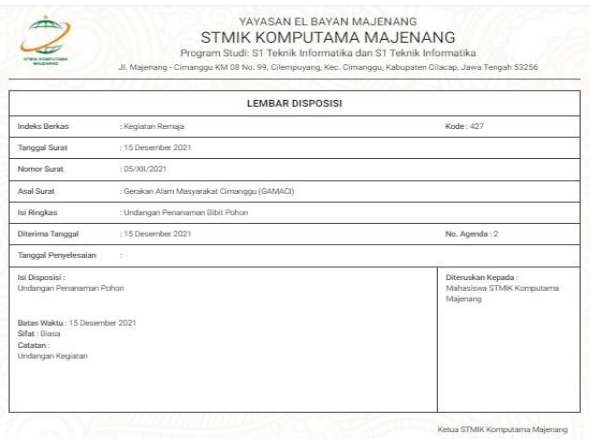

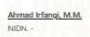

Gambar 21. Output transaksi surat masuk

2) Agenda Surat Masuk

Agenda Surat Masuk dari tanggal 01 Desember 2021 sampai dengan tanggal 31 Desember 2021

\begin{tabular}{|c|c|c|c|c|c|c|c|c|}
\hline Noo & Kede & bil linghka & Raal Surat & Nemar Surut & $\begin{array}{l}\text { Trengal } \\
\text { Surat }\end{array}$ & Nergalida & $\begin{array}{l}\text { Tatgeal } \\
\text { Part }\end{array}$ & Keteratgan \\
\hline 1 & 001 & $\begin{array}{l}\text { Pemblonan } \\
\text { buntuan bah } \\
\text { potan kaye } \\
\text { tatuh }\end{array}$ & $\begin{array}{l}\text { Cerrikan } \\
\text { Alam } \\
\text { Masparibat } \\
\text { Cimargen } \\
\text { (CaMaCf) }\end{array}$ & 001/XE/2021 & \begin{tabular}{|l}
19 \\
Desimber \\
2021
\end{tabular} & $\begin{array}{l}\text { Reahurdika } \\
\text { F.P. }\end{array}$ & $\begin{array}{l}13 \\
\text { Desumber } \\
2021\end{array}$ & $\begin{array}{l}\text { Suat } \\
\text { Pemotonan }\end{array}$ \\
\hline 2 & 427 & $\begin{array}{l}\text { Undaryan } \\
\text { Peuraman } \\
\text { BtitPotion }\end{array}$ & 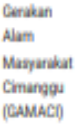 & $05 / 201 / 2621$ & \begin{tabular}{|l}
15 \\
Desemter \\
2021
\end{tabular} & $\begin{array}{l}\text { Dutugas } \\
\text { Dispesiai }\end{array}$ & $\begin{array}{l}15 \\
\text { Desumber } \\
2021\end{array}$ & Undaryan \\
\hline
\end{tabular}

Gambar 22. Output agenda surat masuk 


\section{3) Agenda Surat Keluar}

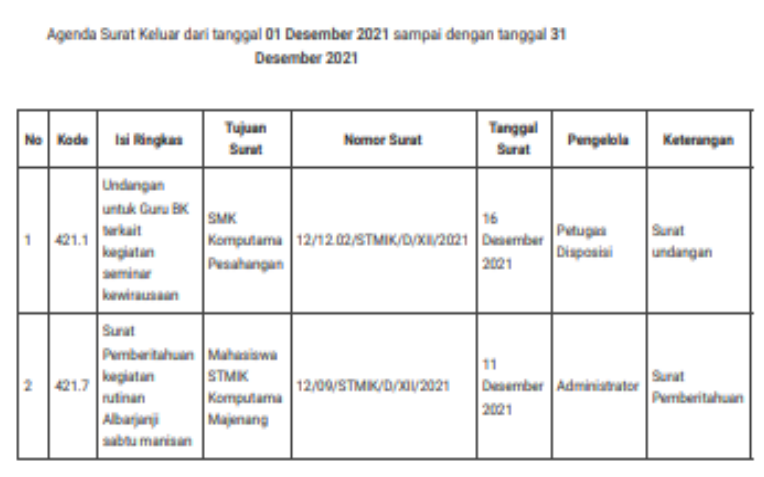

Gambar 23. Output agenda surat keluar

\section{Kesimpulan}

Berdasarkan pembahasan yang telah dilakukan pada bab-bab sebelumnya, maka dapat ditarik beberapa kesimpulan ini yaitu sebagai berikut :

1. Penelitian ini menghasilkan sistem informasi manajemen arsip surat masuk dan surat keluar berbasis web pada STMIK Komputama Majenang, yang dapat diimplemetasikan sesuai dengan kebutuhan dalam pengelolaan surat masuk dan surat keluar agar dapat memudahkan pengelolaan data serta sebagai bentuk perkembangan teknologi informasi dan komputer

2. Memberikan kemudahan bagi STMIK Komputama Majenang dalam mengirim dan mengarsipkan surat masuk dan surat keluar jika diperlukan kedepannya.

\section{Saran}

Berdasarkan penelitian yang telah dilakukan maka dapat dikemukakan saran-saran sebagai berikut :

1. Implementasi sistem yang telah dibangun tentunya dapat dikembangkan kembali seperti menambahkan fitur pemberitahuan (notification) jika ada data disposisi surat yang dikirim antar bidang/bagian jabatan fungsional yang ada di STMIK Komputama Majenang dan status pemberitahuan untuk data surat yang sudah dibaca atau belum.

2. Dalam pengembangan sistem ini belum memperhatikan masalah keamanan data (security), maka untuk itu penelitian lebih lanjut dapat dilengkapi dengan sistem keamanan datanya.

3. Dalam pengembangan kedepannya sistem informasi ini juga dapat diperbaharui lagi dalam hal hal tampilan dan terutama fitur/fungsinya agar bisa ditambahkan. 


\section{Referensi}

Ade Suryadi, Y. S. (2019). Rancang Bangun Sistem Pengelolaan Arsip Surat Berbasis Web. Jurnal Khatulistiwa Informatika, 13-21.

Riswanto, B., \& Mutingudin. (2020). APLIKASI PERSEDIAAN BAHAN BANGUNAN BERBASIS WEB PADA TOKO TB AGENG JAYA CILOPADANG. Jurnal Teknologi Dan Bisnis, 2(1), 69-86. https://doi.org/10.37087/jtb.v2i1.55

Afikah, N. (2020). Sistem Pengelolaan Surat Masuk Dan Surat Keluar Dinas Komunikasi Dan Informatika Di Palembang (KOMINFO). Laporan KuliahKerja Praktek. Program Studi Teknik Informatika Fakultas Ilmu Komputer,Universitas Bina Darma Palembang.

Fauzan Masykur, I. M. (2015). Sistem Administrasi Pengelolaan Arsip Surat MasukDan Surat Keluar . IJNS - Indonesian Journal on Networking and Security, 1-7.

Husaein, A. (2020). Perancangan Sistem Informasi Manajemen Surat . Jurnal Ilmiah MEDIA SISFO, 130-137.

Nugroho, A. C. (2019). Rancang Bangun Sistem Informasi Manajemen Surat. Jurnal Pengembangan IT (JPIT), 146-151.

kennedy, janero, \& fawaid, miftahul . (2019). PERANCANGAN SISTEM INFORMASI PENJUALAN SOFTWARE BERBASIS WEB (STUDI KASUS PT. ELECTRONIC DATA INTERCHANGE INDONESIA). Jurnal Teknologi Dan Bisnis, 1(1), 92-102. https://doi.org/10.37087/jtb.v1i1.58

Rafidah, I. (2019). Sistem Infomasi Pengelolaan Surat Masuk Dan Surat Keluar DiKecamatan Ngemplak Yogyakarta. Tugas Akhir. Program Studi Teknik Informatika-Program Sarjana Fakultas Teknologi Industri, UniversitasIslam Indonesia.

Muniroh, N., \& Muzayyinul Achkam, D. A. . (2019). PERANCANGAN APLIKASI INVENTARISASI SUKU CADANG PERALATAN METEOROLOGI BERBASIS SISTEM OPERASI ANDROID DENGAN DATABASE SQLITE PADA SUB BIDANG INSTRUMENTASI REKAYASA PERALATAN METEOROLOGI BMKG. Jurnal Teknologi Dan Bisnis, 1(1), 66-80. https://doi.org/10.37087/jtb.v1i1.52

Riswanto, B. (2015). Aplikasi Resto Berbasis Android Di D'saung Hall And Resto.Laporan Kerja Praktek. Program Studi Teknik Informatika Fakultas Teknik, Universitas Muhammadiyah Purwokerto.

Saifudin, A. Y. (2019). Sistem Informasi Arsip Surat (SINAU) Berbasis Web PadaKantor Desa Karangsalam Kecamatan Baturraden. Jurnal Sains dan Manajemen, 15-21.

Website. (n.d.). Metode Waterfall. Retrieved from Sekawan Media: https://www.sekawanmedia.co.id/blog/metode-waterfall/

Website. (n.d.). Profil STMIK Komputama. Retrieved from STMIK Komputama Majenang: http://www.stmikkomputama.ac.id/

Website. (n.d.). Tentang STT Terpadu Nurul Fikri. Retrieved from akademik.nurulfikri.ac.id: https://akademik.nurulfikri.ac.id/ 